\title{
Response evaluation in head and neck oncology
}

\author{
Robert Mandic · Jochen A. Werner
}

Published online: 6 January 2010

(C) Springer-Verlag 2010

In this issue you will find the review article "assay-based response evaluation in head and neck oncology: requirements for better decision making" by Dietz and co-workers [1]. This interesting review addresses a major issue in head and neck cancer therapy. A major problem in the treatment of head and neck cancers, particularly head and neck squamous cell carcinomas (HNSCCs), accounting for over $90 \%$ of all malignancies in this area, is unpredictable resistance to chemotherapy and failure after multimodality treatment in general. Being able to identify responders and non-responders prior to therapy induction is therefore of utmost importance.

The authors indicate the difficulties in predicting the treatment outcome of tumors since these are frequently highly heterogeneous in their biological behavior [2] and emphasize the need for a reliable predictive assay. They introduce and discuss different types of assays that have been used for prediction of chemosensitivity in solid cancers such as breast, lung, ovarian, brain and HNSCC tumors [3-5]. The authors particularly point out that in these so-called ex vivo assays, which use the patients own cancer tissue, all cell types that build up a tumor mass are present such as fibroblasts, endothelial cells and the epithelial carcinoma cells themselves. This should have a clear advantage since these assays will likely mimic the real in vivo situation of the tumor. The authors also indicate that for the same reason cell lines are not suitable for the development of reliable assays since cell lines are highly selected tumor stem cells and important cellular

R. Mandic · J. A. Werner $(\bowtie)$

Universitätsklinikum Giessen und Marburg GmbH,

Standort Marburg, Baldingerstraße, 35033 Marburg, Germany

e-mail: wernerj@med.uni-marburg.de tumor tissue constituents such as fibroblasts and endothelial cells are lacking.

However, as much as ex vivo tissues appear suitable to mimic the real in vivo situation there is one important drawback. By having at least three different cell types, chemosensitivity testing can be distorted if one does not distinguish between the single cell types. Stromal cells of the tumor usually are derived from normal body cells, which in general are significantly more resistant to chemotherapy than the respective tumor cells. Therefore, it is essential that a suitable HNSCC chemosensitivity test is capable of selectively testing the epithelial tumor cell population.

Next to these features Dietz et al. define further test criteria such as high feasibility, high predictive accuracy, robust SOPs, quantitative results, getting the results in a reasonable time and being able to perform the tests on small amounts of tumor tissues such as those obtained from tumor biopsies. The authors also discuss the important question if a single biopsy is representative of the whole tumor. Their own data supports the view that single biopsies indeed are representative of the whole tumor.

Lastly, the authors explain why the chemosensitivity test, known as the FLAVINO assay is advantageous or even superior to other test systems. Particularly, they stress the tests ability to account for the flavin-dependent inhibiting effect of cell culture media on chemotherapeutic agents, its ability to correct for the presence of stromal cells and that it carries control (KB) cells for quality purposes.

Dietz et al. conclude that chemosensitivity tests are now suitable and technically mature to be investigated as an additional tool for therapeutic decision making in clinical trials. The authors blamed the low acceptance of chemosensitivity assays as stated by the ASCO in 2004 on the severe lack of controlled clinical studies [6]. Therefore, to 
implement such tests in the daily routine, multicenter studies will be required to evaluate these assays for its suitability to predict therapy outcome. If positive these assays could help sparing a significant subpopulation of head and neck cancer patients from harmful and ineffective therapeutic schemes.

\section{References}

1. Dietz A, Boehm A, Horn IS, Kruber P, Bechmann I, Golusinski W, Niederwieser D, Dollner R, Remmerbach TW, Wittekind C, Dietzsch S, Hildebrandt G, Wichmann G (2009) Assay based response evaluation in head and neck oncology-requirements for better decision making. Eur Arch Otorhinolaryngol. doi:10.1007/ s00405-009-1191-5
2. Cree IA (2009) Chemosensitivity and chemoresistance testing in ovarian cancer. Curr Opin Obstet Gynecol 21(1):39-43

3. Dollner R, Granzow C, Werner JA, Dietz A (2004) Is there a role for chemosensitivity tests in head and neck cancer? Onkologie 27(3):310-315

4. Fruehauf JP (2002) In vitro assay-assisted treatment selection for women with breast or ovarian cancer. Endocr Relat Cancer 9(3):171-182

5. Gazdar AF, Steinberg SM, Russell EK, Linnoila RI, Oie HK, Ghosh BC, Cotelingam JD, Johnson BE, Minna JD, Ihde DC (1990) Correlation of in vitro drug-sensitivity testing results with response to chemotherapy and survival in extensive-stage small cell lung cancer: a prospective clinical trial. J Natl Cancer Inst 82(2):117-124

6. Schrag D, Garewal HS, Burstein HJ, Samson DJ, Von Hoff DD, ASCO Somerfield MR Working Group on Chemotherapy Sensitivity Resistance Assays (2004) American Society of Clinical Oncology Technology Assessment: chemotherapy sensitivity and resistance assays. J Clin Oncol 22(17):3631-3638 